\title{
Calcium-dependent Nr4a1 expression in mouse Leydig cells requires distinct AP1/CRE and MEF2 elements
}

\author{
Houssein S Abdou', Nicholas M Robert ${ }^{1}$ and Jacques J Tremblay',2 \\ ${ }^{1}$ Reproduction, Mother and Youth Health, CHUQ Research Centre, Quebec, Canada \\ ${ }^{2}$ Centre for Research in Biology of Reproduction, Department of Obstetrics, Gynecology, \\ and Reproduction, Faculty of Medicine, Université Laval, Quebec, Canada
}

Correspondence should be addressed to J J Tremblay Email

Jacques-J.Tremblay@ crchudequebec.ulaval.ca

\begin{abstract}
The nuclear receptor NR4A1 is expressed in steroidogenic Leydig cells where it plays pivotal roles by regulating the expression of several genes involved in steroidogenesis and male sex differentiation including Star, HSD3B2, and Ins/3. Activation of the CAMP and $\mathrm{Ca}^{2+}$ signaling pathways in response to $\mathrm{LH}$ stimulation leads to a rapid and robust activation of $\mathrm{Nr} 4 \mathrm{a} 1$ gene expression that requires the $\mathrm{Ca}^{2+} / \mathrm{CAMKI}$ pathway. However, the downstream transcription factor(s) have yet to be characterized. To identify potential $\mathrm{Ca}^{2+} / \mathrm{CaM}$ effectors responsible for hormone-induced Nr4a1 expression, MA-10 Leydig cells were treated with forskolin to increase endogenous CAMP levels, dantrolene to inhibit endoplasmic reticulum $\mathrm{Ca}^{2+}$ release, and W7 to inhibit CaM activity. We identified $\mathrm{Ca}^{2+-}$ responsive elements located in the discrete regions of the $\mathrm{Nr} 4 \mathrm{a} 1$ promoter, which contain binding sites for several transcription factors such as AP1, CREB, and MEF2. We found that one of the three AP1/CRE sites located at $-255 \mathrm{bp}$ is the most responsive to the $\mathrm{Ca}^{2+}$ signaling pathway as are the two MEF2 binding sites at -315 and $-285 \mathrm{bp}$. Furthermore, we found that the hormone-induced recruitment of phospho-CREB and of the co-activator p300 to the Nr4a1 promoter requires the $\mathrm{Ca}^{2+}$ pathway. Lastly, siRNAmediated knockdown of CREB impaired NR4A1 expression and steroidogenesis. Together, our data indicate that the $\mathrm{Ca}^{2+}$ signaling pathway increases $\mathrm{Nr} 4 \mathrm{a} 1$ expression in MA-10 Leydig cells, at least in part, by enhancing the recruitment of coactivator most likely through the MEF2, AP1, and CREB transcription factors thus demonstrating an important interplay between the $\mathrm{Ca}^{2+}$ and CAMP pathways in regulating Nr4a 1 expression.
\end{abstract}

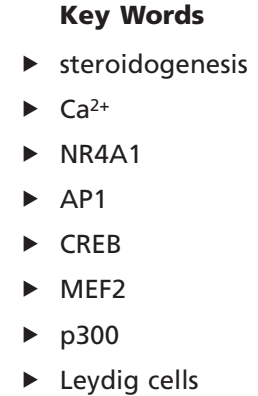

Journal of Molecular Endocrinology (2016) 56, 151-161

\section{Introduction}

Binding of $\mathrm{LH}$ to its receptor on the surface of Leydig cells triggers the production of several second messengers including cAMP, $\mathrm{Ca}^{2+}, \mathrm{DAG}$, and $\mathrm{IP}_{3}$, which in turn activate various transcription factors leading to increased gene expression and ultimately a physiological response, i.e. enhanced steroid hormone biosynthesis. Previously, the classical cAMP pathway was thought to account for most of the LH-induced steroidogenesis in Leydig cells (reviewed in Hansson et al. 2000). However, several reports have also established the requirement of a transient increase in cytoplasmic $\mathrm{Ca}^{2+}$ following trophic hormone stimulation for proper steroidogenesis to occur (Dufau et al. 1984, Sullivan \& Cooke 1986).

Published by Bioscientifica Ltd. 
Two L-type $\mathrm{Ca}^{2+}$ channels receptors are present in the endoplasmic reticulum (ER) of murine Leydig cells: the ryanodine receptors (RyRs) I, II, and III, and the inositol triphosphate receptors (IP3Rs) I, II, and III (Costa et al. 2010). Activation of the RyRs has been shown to be the primary mediator of the $\mathrm{Ca}^{2+}$ signaling pathway in Leydig cells steroidogenesis (Costa et al. 2010, Abdou et al. 2013). We recently have shown that the RyR and $\mathrm{Ca}^{2+}$-calmodulin (CaM) inhibitors, ryanodine and W7, respectively, impair steroidogenesis in the MA-10 Leydig cell line through a decrease in the expression and promoter activity of STAR (Abdou et al. 2013). The main $\mathrm{Ca}^{2+} / \mathrm{CaM}$ kinase involved in Star expression in Leydig cells is CAMKI (Martin et al. 2008). Furthermore, the expression and promoter activity of Nr4a1, a mediator of hormone-stimulated Star expression (Martin et al. 2008, Abdou et al. 2013), were also compromised upon disruption of the $\mathrm{Ca}^{2+}$ pathway (Martin et al. 2008, Abdou et al. 2013). Thus, our data identified a transcriptional cascade initiated by $\mathrm{Ca}^{2+}$ release from ER stores in the regulation of steroid hormone biosynthesis in Leydig cells.

The NR4A1 (NUR77, NGFI-B) nuclear receptor is part of the subfamily of NR4A nuclear receptors along with NR4A2 (NURR1) and NR4A3 (NOR1). Their expression is modulated by several agents, including but not limited to trophic hormones, $\mathrm{Ca}^{2+}$, and growth factors (reviewed in (Li et al. 2006)). NR4A1 is expressed in adrenal and gonadal cells, where it regulates the expression of several genes involved in steroidogenesis including Star (Martin et al. 2008), Cyp17a1 (Zhang \& Mellon 1997), HSD3B2 (Bassett et al. 2004a, Martin \& Tremblay 2005), and Cyp11b2 (Bassett et al. 2004b).

In steroidogenic Leydig cells, NR4A1 protein and Nr4a1 mRNA levels are induced as early as $30 \mathrm{~min}$ post LH/hCG stimulation and peak at $2 \mathrm{~h}$ before rapidly decreasing to undetectable levels by $3 \mathrm{~h}$ (Song et al. 2001). A similar kinetic was observed in MA-10 Leydig cells treated with forskolin (Fsk) (Martin et al. 2008). LH/ Fsk-induced $\mathrm{Nr} 4 a 1$ expression is blunted in the presence of inhibitors of RyRs and CaM (Abdou et al. 2013), protein kinase A (PKA) (Song et al. 2001, Martin et al. 2009), phosphoinositide-3 kinase (PI3K) (Song et al. 2001), and CAMK (Martin et al. 2009).

While it is known that the $\mathrm{Ca}^{2+} / \mathrm{CAMKI}$ signaling pathways is important for Nr4a1 expression in Leydig cells (Martin et al. 2008, Abdou et al. 2013), the specific transcription factors downstream of this pathway, and thus affected by the inhibitors ryanodine and W7, remain poorly characterized. In this study, we found that several response elements, including AP1, CRE, and MEF2, within the proximal Nr4a1 promoter are sensitive to the disruption of the $\mathrm{Ca}^{2+}$ signaling pathway by either dantrolene, which inhibits intracellular $\mathrm{Ca}^{2+}$ release by the ER, and W7, a CaM inhibitor. Mutation of these elements abolished the effect of either inhibitors. We also found that the Fsk-induced recruitment of phosphorylated CREB and of the ubiquitous coactivator p300 to the proximal Nr4a1 promoter was decreased following treatment with either dantrolene or W7. Together, these results suggest that the transcription factors that bind to these elements activate Nr4a1 gene expression in MA-10 Leydig cells in a $\mathrm{Ca}^{2+}$ dependent manner by modulating the recruitment of the coactivator $\mathrm{p} 300$.

\section{Materials and methods}

\section{Cell culture}

The mouse MA-10 Leydig cell line (Ascoli 1981) was provided by Dr Mario Ascoli (University of Iowa, Iowa City, Iowa) and maintained in DMEM-F12 supplemented with penicillin and streptomycin, 15\% horse serum, and incubated at $37^{\circ} \mathrm{C}$ in $5 \% \mathrm{CO}_{2}$.

\section{Chemicals}

The RyR inhibitor dantrolene and the calmodulin (CaM) inhibitor W7 hydroxychloride were obtained from Tocris Bioscience (Minneapolis, MN) and previously validated in MA-10 Leydig cells (Abdou et al. 2013). Forskolin (Fsk) and 8-bromo-cAMP (8Br-cAMP) were purchased from Sigma-Aldrich.

\section{Plasmids}

The -331 to +50 bp rat $N r 4 a 1$ promoter and the various NIR-A, NIR-B, and NIR-C reporter constructs were described previously (Martin et al. 2009). The three TGCGTCA AP1/CRE elements located at $-255,-233$, and $-91 \mathrm{bp}$ were mutated to TGCacCA by site-directed mutagenesis using the QuikChange Site-Directed Mutagenesis Kit (Agilent Technologies) along with the following three pairs of oligonucleotides (the AP1/CRE site is underlined and the mutated nucleotides are in lowercase): -255 bp sense 5'-ACA ATC CGC GCT CCC TGC acC AAT GGA ACC CCG CGT GCG-3' and -255 antisense 5'-CGC ACG CGG GGT TCC ATT Ggt GCA GGG AGC GCG GAT TGT-3'; -233 bp sense 5'-CAA TGG AAC CCC GCG TGC acC ACG CGC GCA GAC ATT CC-3'

Published by Bioscientifica Ltd. 
and -233 bp antisense 5'-GGA ATG TCT GCG CGC GTG gtG CAC GCG GGG TTC CAT TG-3'; -91 bp sense 5'-GCT CGC CGG GCC GTG TGC acC AGT GGC GCC CCC GCC CCT C-3' and -91 bp antisense 5'-GAG GGG CGG GGG CGC CAC TGg tGC ACA CGG CCC GGC GAG C-3'. The constructs harboring mutations in the two MEF2 elements located at -319 and -285 bp were described previously (Daems et al. 2014). The expression vector for MEF2D was described previously (Daems et al. 2014). The cJUN expression vector (Teyssier et al. 2001) was obtained from Dr Dany Chalbos (Institut National de la Santé et de la Recherche Médicale, Endocrinologie Moléculaire et Cellulaire des Cancers, Montpellier, France). The CREB expression vector (Mayr \& Montminy 2001) was provided by Dr. Marc Montminy (The Salk Institute for Biological Studies, La Jolla, California).

\section{Protein purification and western blots}

Nuclear extracts and western blots were performed as described previously (Martin et al. 2008, Abdou et al. 2014). For each experiment, MA-10 Leydig cells were cultured in serum-free media in the presence of either vehicle, Fsk $(10 \mu \mathrm{M})$ alone, Fsk + dantrolene $(150 \mu \mathrm{M})$, Fsk + W7 $(40 \mu \mathrm{M})$ for $1 \mathrm{~h}$ before nuclear extracts preparation. Each experiment was performed at least 3 times. The antisera used for detection of NR4A1 (M-210), LAMIN B (C-20) and CREB (H-74) were purchased from Santa Cruz Biotechnology.

\section{Transfections and reporter assays}

Mouse MA-10 Leydig cells were transfected, lysed, and lysates analyzed as described previously (Martin et al. 2008, Martin et al. 2009). The cells were treated with either vehicle, 8Br-cAMP (0.5 mM), 8Br-cAMP + dantrolene $(150 \mu \mathrm{M})$, or $8 \mathrm{Br}-\mathrm{cAMP}+\mathrm{W} 7(40 \mu \mathrm{M})$ for $4 \mathrm{~h}$ before being lysed. When indicated, $100 \mathrm{ng}$ of expression vector (cJUN, CREB, and MEF2D) was also co-transfected with the luciferase reporter construct.

\section{Chromatin immunoprecipitation assay}

MA-10 Leydig cell were treated for 30 min with vehicle, Fsk $(10 \mu \mathrm{M})$, Fsk+dantrolene $(150 \mu \mathrm{M})$, or Fsk+W7 $(40 \mu \mathrm{M})$ in serum-free media. The cells were next cross-linked with $1 \%$ formaldehyde for $10 \mathrm{~min}$ at $37^{\circ} \mathrm{C}$, washed twice with cold PBS and then scraped and transferred into microtubes. The experimental procedures can be found in Abdou et al. (2014). Five $\mu$ g of either IgG (negative control) or anti-p300, anti-CREB, or anti-pCREB antisera (Santa Cruz Biotechnology) were used as described previously (Abdou et al. 2014). PCR amplification of the -284 to -3 bp region of murine $N r 4 a 1$ promoter was used to confirm the recruitment of the factors.

\section{Transfections of siRNAs}

For knockdown experiments, $150 \mathrm{nM}$ of siRNA oligos were used per $60 \mathrm{mM}$ plate along with $16 \mu \mathrm{L}$ of Jetprime/200 $\mu \mathrm{L}$ Jetprime buffer. In some cases, the amounts were scaled down proportionally when smaller wells were used. Knockdown of CREB was achieved by using a combination (1:1:1 ratio) of the following three pairs of siRNA oligos
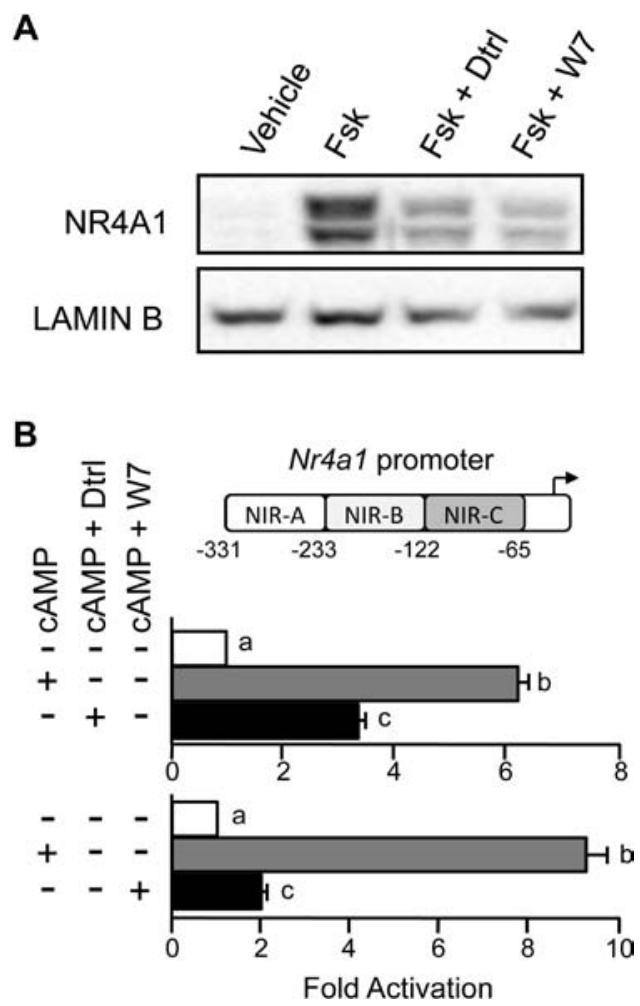

\section{Figure 1}

Inhibition of the $\mathrm{Ca}^{2+-s e n s i n g ~ p r o t e i n ~ c a l m o d u l i n ~(C a M) ~ a n d ~ t h e ~}$ ryanodine receptors impair hormone-induced NR4A1 expression in MA-10 Leydig cells. (A) NR4A1 protein levels were determined by western blot using nuclear extracts from MA-10 Leydig cells treated for $1 \mathrm{~h}$ with either vehicle, Fsk $(10 \mu \mathrm{M})$, Fsk + dantrolene $(150 \mu \mathrm{M})$, or Fsk + W7 $(40 \mu \mathrm{M})$. Representative blots from three independent experiments are shown. LAMIN B was used as a loading control. The NR4A1 protein is seen as two bands where one represents a phosphorylated form, as previously shown (Fahrner et al. 1990, Martin et al. 2008). (B) MA-10 Leydig cells were transfected with a $-331 \mathrm{bp}$ Nr4a 1 reporter and treated with vehicle, $8 \mathrm{Br}$-cAMP $(0.5 \mathrm{mM})$, $8 \mathrm{Br}$-CAMP + dantrolene $(150 \mu \mathrm{M})$, or $8 \mathrm{Br}-\mathrm{CAMP}+\mathrm{W} 7(40 \mu \mathrm{M})$ as indicated. Results are shown as fold activation over vehicle \pm S.E.M. Different letters indicate statistically significant differences $(P<0.05)$.

Published by Bioscientifica Ltd. 
(only the sense strand is shown): 1st GCC CAG CAA CCA AGU UGU UGU UCA A, 2nd AGG GAG GAG CAA UAC AGC UGG CUA A, 3rd CAC GGA AGA GAG AGG UCC GUC UAA U.

\section{Progesterone quantification}

Progesterone levels from MA-10 Leydig cells were quantified by ELISA (Cayman Chemical) as described previously (Abdou et al. 2014). For basal progesterone levels, $50 \mu \mathrm{L}$ of media was diluted 41 times, $50 \mu \mathrm{L}$ of which was used in the assay. For Fsk-stimulated progesterone levels, $50 \mu \mathrm{L}$ of the media was diluted 441 times and $50 \mu \mathrm{L}$ of the dilution was subsequently used. Values were normalized to the proteins levels extracted from each well and results presented as $\mathrm{ng} / \mathrm{mg}$ of total proteins.

\section{Statistical analysis}

For the multiple group comparisons, statistical analyses were performed by using a one-way ANOVA followed by the Bonferroni post hoc test. For all single comparisons between two experimental groups, one-tailed paired Student's $t$ tests were performed. A $P<0.05$ was considered to be significant. All statistical analyses were
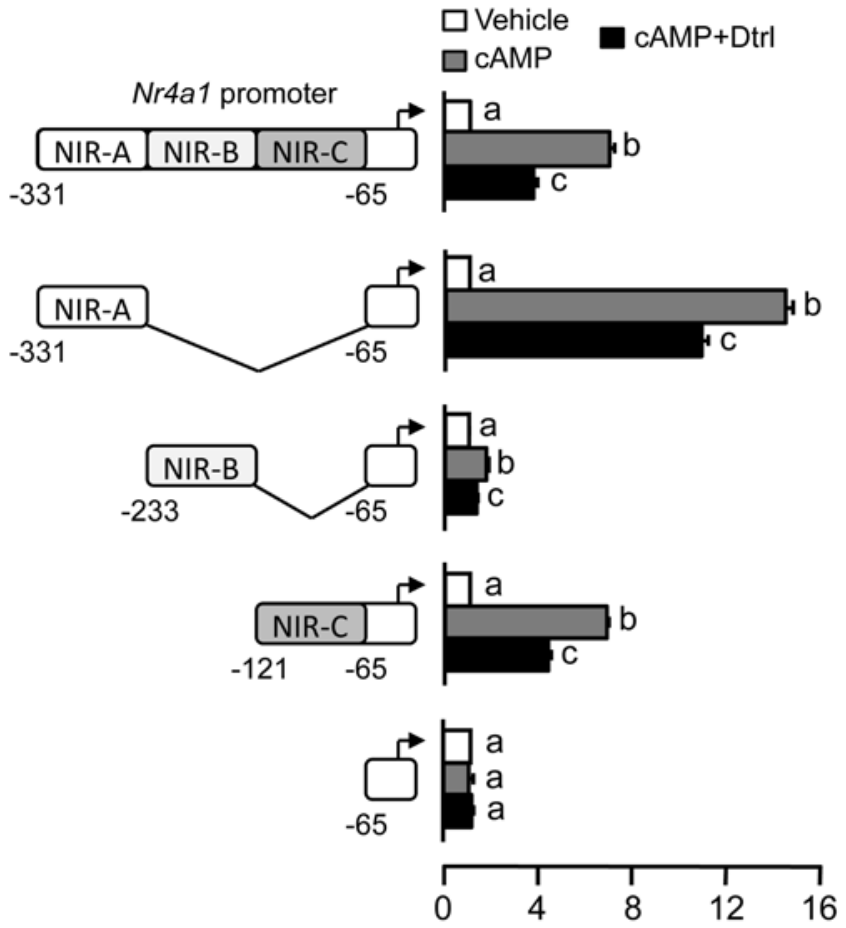

Fold Activation done using SigmaStat software package (Systat Software Inc., San Jose, CA).

\section{Results}

\section{Blocking $\mathrm{Ca}^{2+}$ release from intracellular stores inhibits Fsk-induced $\mathbf{N r 4 a} 1$ expression and promoter activity}

In a previous study, we showed that RyR inhibition using Ryanodine, which inhibits $\mathrm{Ca}^{2+}$ release from internal stores, blunts hormone-induced steroidogenesis and Star gene expression, and that NR4A1 expression was also decreased (Abdou et al. 2013). To gain more insights into the mechanisms involved in $\mathrm{Ca}^{2+}$-dependent NR4A1 expression in response to forskolin (Fsk)/cAMP, we evaluated the effect of dantrolene and W7, which are known inhibitors of $\mathrm{Ca}^{2+}$ release and CaM activity, respectively. The effects of the inhibitors were first assessed on NR4A1 protein levels. As expected, a strong increase in NR4A1 expression was observed in the presence of Fsk (Fig. 1A). However, this increase was significantly reduced in the presence of either dantrolene or W7 (Fig. 1A). Furthermore, both dantrolene and W7 decreased the cAMP-induced activity of the -331 bp Nr4a1 reporter by $\sim 50 \%$ and
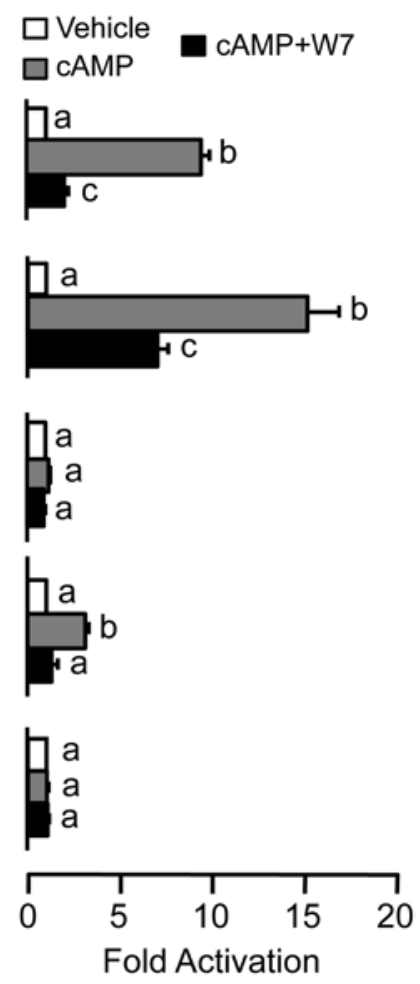

Figure 2

The $\mathrm{Ca}^{2+}$ pathway targets several regions in the Nr4a1 promoter. MA-10 Leydig cells were transiently transfected with various $\mathrm{Nr} 4 \mathrm{a} 1$ reporter constructs: -331 to $+50 \mathrm{bp}$ (NIR-ABC), -331 to -233 (NIR-A), -233 to -122 (NIR-B), -122 to +50 (NIR-C), and -65 to +50 (minimal promoter). Cells were then treated with either vehicle, $8 \mathrm{Br}$-cAMP (0.5 mM), 8Br-cAMP + dantrolene $(150 \mu \mathrm{M}$, left panel), or $8 \mathrm{Br}-\mathrm{CAMP}+\mathrm{W} 7(40 \mu \mathrm{M}$, right panel). Results are shown as fold activation over vehicle \pm S.E.M. Different letters indicate statistically significant differences $(P<0.05)$. 
$\sim 80 \%$, respectively (Fig. 1B). This is in agreement with the previously published data using a -747 to $+50 \mathrm{bp}$ Nr4a1 reporter (Abdou et al. 2013). Collectively, these data indicate that hormone/Fsk/cAMP-induced NR4A1 expression requires adequate $\mathrm{Ca}^{2+}$ signaling in the MA-10 Leydig cell line.

It was previously shown that the Nr4a1 proximal promoter ( -331 to +50 bp) can be divided into three regions with distinct activities: NIR-A (-331 to $-233 \mathrm{bp}$ ), NIR-B (-233 to $-121 \mathrm{bp}$ ), and NIR-C (-121 to -65 bp) (Martin et al. 2009). The NIR-A and NIR-C regions are hormone/cAMP responsive, while NIR-B mediates most of the basal promoter activity (Martin et al. 2009). However, the $\mathrm{Ca}^{2+}$-responsive region(s) have never been studied. To better locate the region within the Nr4a1 promoter that is targeted by the $\mathrm{Ca}^{2+}$ signaling pathway, the inhibitors dantrolene and W7 were used with the NIR reporter constructs. As shown in Fig. 2, the cAMP-induced activity of the NIR-A and NIR-C regions (the cAMPresponsive regions) were the most affected by dantrolene

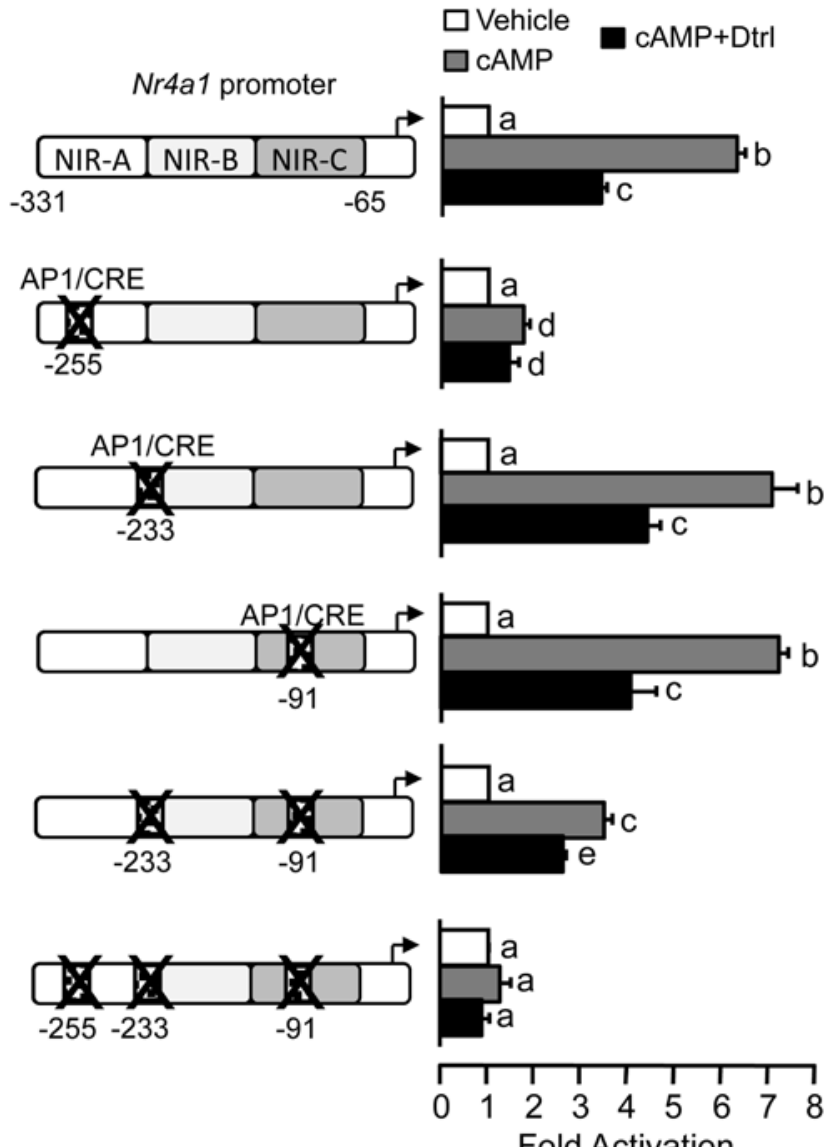

Fold Activation and W7 when compared with NIR-B region or to the minimal promoter which are essentially unresponsive to cAMP (Fig. 2). These results indicate that the $\mathrm{Ca}^{2+}$ responsive elements are mainly located in the NIR-A and NIR-C regions of the Nr4a1 promoter.

\section{$\mathrm{Ca}^{2+}$ responsiveness of the $\mathrm{Nr} 4 \mathrm{a} 1$ promoter requires intact AP1/CRE and MEF2 elements}

In silico analysis of these regions revealed the presence of binding sites for several transcription factors. These include AP1/CRE half sites located at -255 bp (NIR-A), -233 bp (NIR-B), and -91 bp (NIR-C), as well as MEF2 elements located at $-319 \mathrm{bp}$ and $-285 \mathrm{bp}$ (NIR-A). The AP1 and CREB transcription factors have been shown to bind and activate the Nr4a1 promoter mostly through these AP1/CRE (Inaoka et al. 2008), while MEF2 is recruited to activate the Nr4a1 promoter via the two MEF2 elements (Daems et al. 2014). Importantly, these transcription factors (AP1, CREB, and MEF2) are known to be activated by the $\mathrm{Ca}^{2+}$ pathway in other systems (Tsuda et al. 1986,
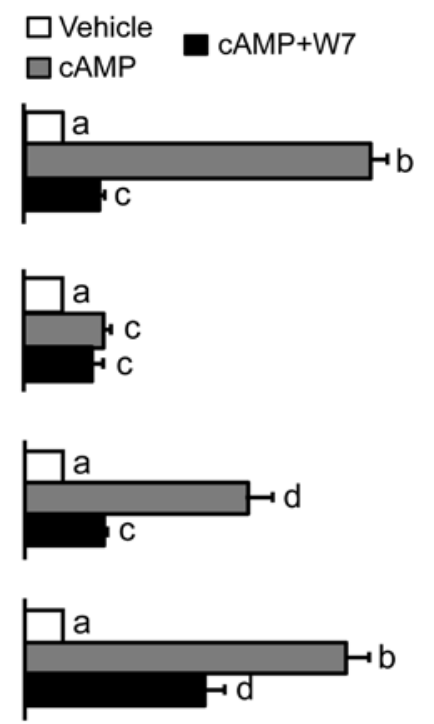

\section{Figure 3}

The $\mathrm{Ca}^{2+}$ signaling pathway acts primarily via the -255 bp AP1/ CRE element. MA-10 Leydig cells were transiently transfected with the rat NIR-ABC Nr4a1 promoter region either wild type or harboring mutations (individual or combined as indicated by a large $\mathrm{X}$ ) in the three AP1/CRE elements $(-255 \mathrm{bp},-233 \mathrm{bp}$, $-91 \mathrm{bp})$. Cells were then treated with either vehicle, $8 \mathrm{Br}$-cAMP (0.5 mM), 8Br-cAMP + dantrolene $(150 \mu \mathrm{M}$, left panel), or $8 \mathrm{Br}-\mathrm{CAMP}+\mathrm{W} 7(40 \mu \mathrm{M}$, right panel). Results are shown as fold activation over vehicle \pm S.E.M. Different letters indicate statistically significant differences $(P<0.05)$. 
Sheng et al. 1990, Sheng et al. 1991, Youn \& Liu 2000, Stocco et al. 2002, Linseman et al. 2003).

We therefore tested whether the $\mathrm{Ca}^{2+}$ responsiveness of the Nr4a1 promoter involves the AP1/CRE and MEF2 elements. When the AP1/CRE element at -255 bp was mutated in the context of the -331 bp Nr4a1 reporter, the cAMP-dependent stimulation was significantly reduced from 6- to 9-fold to 2-fold (Fig. 3). Consistent with this, inhibition of either $\mathrm{Ca}^{2+}$ release from the ER by dantrolene or of CaM activity by W7 had no effect on the activity of -331 bp Nr4a1 promoter mutated in the -255 AP1/CRE element (Fig. 3). Mutation of the other AP1/CRE sites at -233 bp and -91 bp did not affect cAMP responsiveness of the promoter, and was still repressed by dantrolene and W7 as efficiently as the WT reporter (Fig. 3). However, simultaneous mutation of both $-233 \mathrm{bp}$ and $-91 \mathrm{bp}$ AP1/CRE sites showed reduced cAMP responsiveness (3 vs 6- to 9-fold for WT) and a reduced sensitivity to the inhibitors dantrolene and W7 (25\% reduction compared with $50-75 \%$ for the WT reporter; $P<0.05$ one-tailed paired Student's $t$ test) (Fig. 3). Lastly, a -331 bp Nr4a1 reporter harboring mutations in all three AP1/CRE sites was no longer responsive to cAMP and insensitive to dantrolene and W7 (Fig. 3). Together, the results suggest that of the three AP1/CRE sites, the one located at - $255 \mathrm{bp}$ is the most responsive to the $\mathrm{Ca}^{2+}$-signaling pathway in MA-10 Leydig cells.

Several reports identified MEF2 as an essential effector of the $\mathrm{Ca}^{2+}$-signaling pathway in various cell types including cardiomyocytes and myoblasts (Lu et al. 2000, McKinsey et al. 2000, Passier et al. 2000), T-cells (Woronicz et al. 1995), and more recently steroidogenic Leydig cells (Daems et al. 2014). To test whether the $\mathrm{Ca}^{2+}$-signaling pathway regulates $\mathrm{Nr} 4 \mathrm{a} 1$ promoter activity through MEF2 transcription factors, we treated the MA-10 Leydig cells with cAMP and with either dantrolene or W7 following the transfection of a -331 bp Nr4a1 reporter, either wild-type or mutated, in both MEF2 elements. As shown in Fig. 4, Nr4a1 promoter activity was increased in the presence of cAMP and this cAMP-mediated increase was reduced (from 6- to 4-fold) when the MEF2 elements were mutated, as expected (Daems et al. 2014). Consistent with data presented in Figs 2 and 3, the inhibitors dantrolene and W7 repressed the cAMPinduced activity of the wild type -331 bp Nr4a1 reporter. However, dantrolene and W7 had no effect on the cAMP responsiveness of the $-331 \mathrm{bp}$ reporter mutated in the MEF2 elements (Fig. 4). The fact that the remaining cAMP responsiveness of the MEF2-mutated -331 bp reporter was unaltered by the inhibitors indicates that the $\mathrm{Ca}^{2+}$ pathway also acts via the MEF2 elements in the Nr4a1 promoter.

We next tested whether the $\mathrm{Ca}^{2+}$ signaling pathway acts, at least in part, via the transcription factors cJUN, CREB, and MEF2D, which are known to bind to the AP1/CRE and MEF2 elements in the Nr4a1 promoter in MA-10 steroidogenic cells (Inaoka et al. 2008, Martin et al. 2009, Daems et al. 2014). This was assessed by overexpressing either cJUN, CREB, or MEF2D in order to determine if this could rescue the repressive effects of dantrolene and W7 on the cAMP-induced Nr4a1 promoter activity. As shown in Fig. 5, the repressive effects of dantrolene and W7 were lost in the presence of exogenously expressed cJUN, CREB, or MEF2D. This indicates that these transcription factors are likely downstream effectors of the $\mathrm{Ca}^{2+}$ pathway in MA-10 Leydig cells.

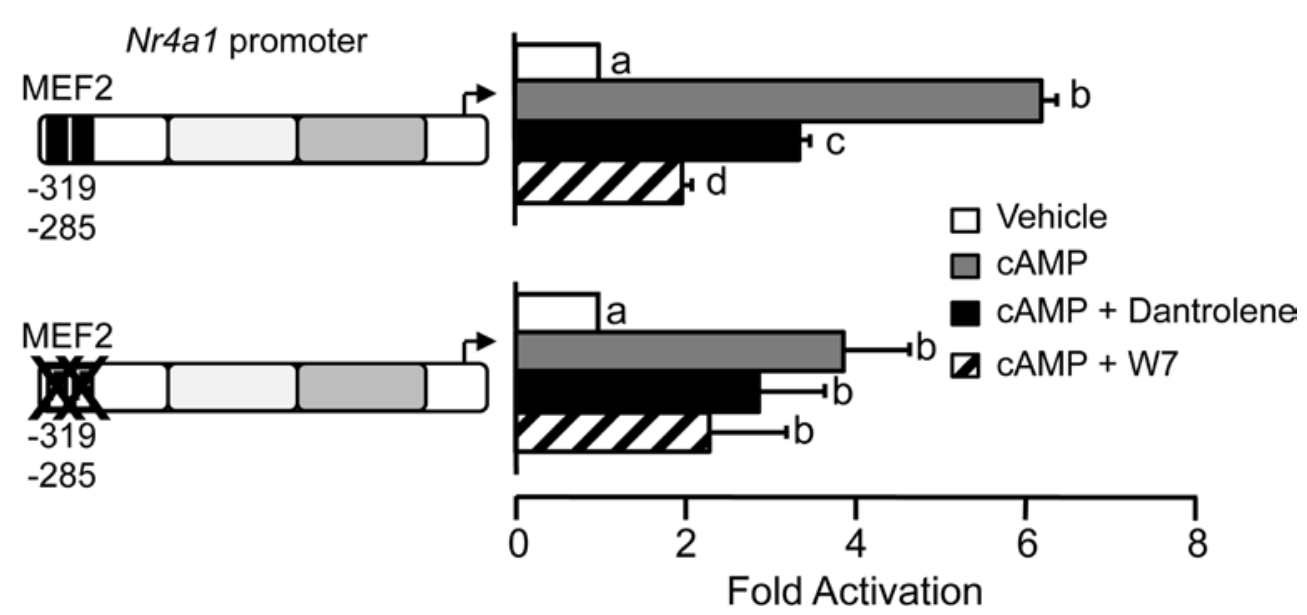

Figure 4

The $\mathrm{Ca}^{2+}$ signaling pathway requires the MEF2 elements within the proximal Nr4a1 promoter. MA-10 Leydig cells were transiently transfected with a rat NIR-ABC Nr4a1 promoter region either wild type or harboring mutations (depicted by a large $X$ ) in the two MEF2 elements ( $-319 \mathrm{bp}$ and $-285 \mathrm{bp}$ ) and treated with either vehicle (open bars), 8Br-cAMP (0.5 mM, gray bars), $8 \mathrm{Br}-\mathrm{cAMP}+$ dantrolene $(150 \mu \mathrm{M}$, black bars), or 8Br-cAMP+W7 (40 $\mu \mathrm{M}$, hatched bars). Results are shown as fold activation over vehicle \pm s.E.M. Different letters indicate statistically significant differences $(P<0.05)$. 
The $\mathrm{Ca}^{2+-s i g n a l i n g ~ p a t h w a y ~ m o d u l a t e s ~ p h o s p h o-C R E B ~}$ and p300 recruitment to the $\mathbf{N r} 4 a 1$ promoter

In other cells, the MEF2 transcription factors regulates Nr4a1 expression by modulating the recruitment of transcriptional co-activators such as p300 (Youn et al. 2000) and co-repressors including histone deacetylases (HDACs) 1, 2, 4, and 5 (Lu et al. 2000, McKinsey et al. 2000, Youn \& Liu 2000). The leucine-zipper factors cJUN and CREB, known to dimerize (Hai \& Curran 1991), activate transcription in a CBP/p300-dependent manner in other cells ((Kim et al. 2005, Yamasaki et al. 2009) and reviewed in (Vo \& Goodman 2001)). As these transcription factors are expressed in Leydig cells, regulate $\mathrm{Nr} 4 a 1$ expression, and their binding sites are targeted by the $\mathrm{Ca}^{2+}$ pathway, we used chromatin immunoprecipitation (ChIP) assays to test the possibility that the $\mathrm{Ca}^{2+}$ pathway might modulate p300 and CREB recruitment to the proximal $\mathrm{Nr} 4 a 1$ promoter (Fig. $6 \mathrm{~A}$ ). As shown in Fig. 6B, Fsk treatment led to an increase in p300

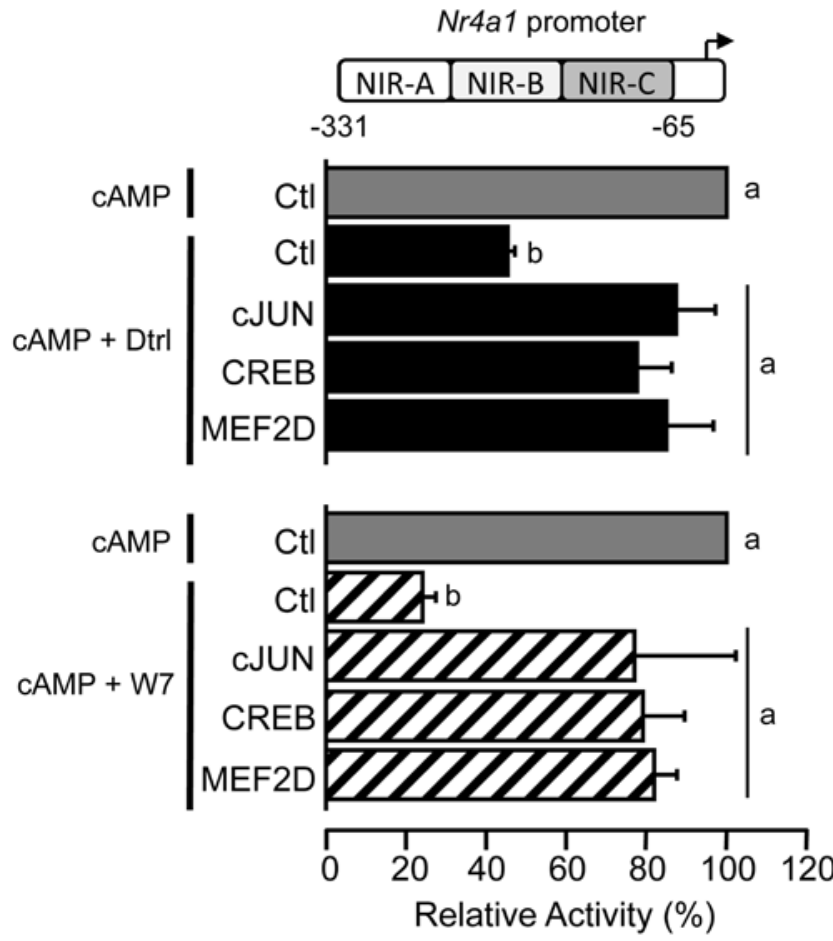

Figure 5

Overexpression of CJUN, CREB, or MEF2D rescues the inhibitory effects of dantrolene and $\mathrm{W} 7$ on the proximal Nr4a1 promoter. MA-10 Leydig cells were transiently transfected with the rat NIR-ABC Nr4a1 promoter region along with an empty expression vector or expression vectors for CJUN, CREB, or MEF2D as indicated and treated with either 8Br-CAMP (0.5 mM, gray bars), $8 \mathrm{Br}-\mathrm{cAMP}+$ dantrolene $(150 \mu \mathrm{M}$, black bars), or $8 \mathrm{Br}$-cAMP + W7 ( $40 \mu \mathrm{M}$, hatched bars). Results are shown as $\%$ activity \pm S.E.M. relative to the activity of the reporter treated with $8 \mathrm{Br}$-CAMP, which was arbitrarily set at $100 \%$. Different letters indicate statistically significant differences $(P<0.05)$. recruitment to the $\mathrm{Nr} 4 \mathrm{a} 1$ promoter as previously observed in MA-10 Leydig cells (Abdou et al. 2014). However, this increase was abolished in the presence of dantrolene or W7 (Fig. 6B). While CREB recruitment to the Nr4a1 promoter was unchanged following Fsk stimulation, phosphorylated CREB (pCREB) recruitment was increased (Fig. 6C). This increase in pCREB recruitment was, however, lost in the presence of dantrolene or W7 (Fig. 6C). This indicates that the $\mathrm{Ca}^{2+}$-signaling pathway increases $\mathrm{Nr} 4 a 1$ gene
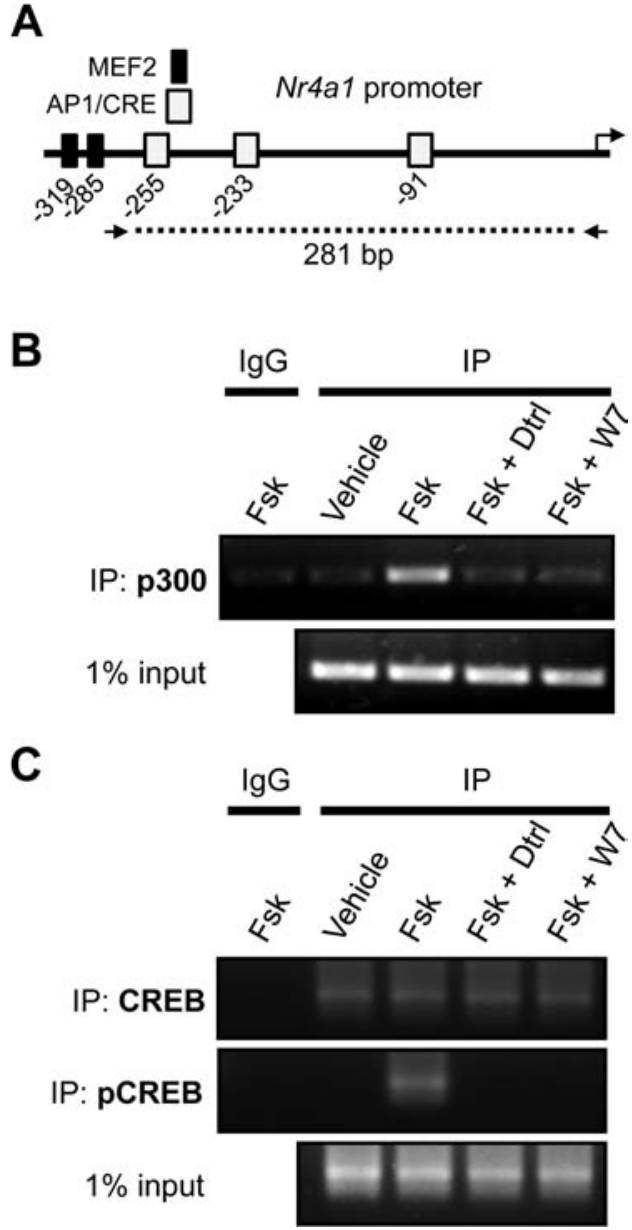

Figure 6

Recruitment of p300 and pCREB to the proximal Nr4a1 promoter in MA-10 Leydig cells requires an intact $\mathrm{Ca}^{2+}$ signaling pathway. (A) Schematic representation of the Nr4a1 locus that was targeted in the ChIP assays. The position of the AP1/CRE (gray rectangles) and MEF2 (black rectangles) elements is shown. The 281 bp region that was amplified is represented by the dotted line. (B) MA-10 Leydig cells were treated for 30 min with DMSO, Fsk $(10 \mu \mathrm{M})$, Fsk + dantrolene $(150 \mu \mathrm{M})$, or Fsk +W7 $(40 \mu \mathrm{M})$ in a serum-free media and chromatin immunoprecipitation (ChIP) experiments were performed to assess p300 recruitment to the -284 to -3 bp region of the Nr4a1 promoter. (C) The conditions described in (B) were used to assess CREB and phosphorylated CREB (pCREB) recruitment to the -284 to -3 bp region of the $N r 4 a 1$ promoter. A non-specific antibody (IgG) was used as a negative control and $1 \%$ of the sonicated extract was used as input.

Published by Bioscientifica Ltd. 
expression, at least in part, by enhancing the recruitment of co-activator most likely through the AP1 (cJUN) and pCREB transcription factors.

\section{Depletion of CREB in MA-10 Leydig cells impairs NR4A1 expression and steroidogenesis}

As the knockdown of MEF2A/2D has already been shown to reduce Nr4a1 expression and steroid hormone production in MA-10 Leydig cells (Daems et al. 2014, Daems et al. 2015), the contribution of the cJUN/CREB complex to these processes was next evaluated. Activated cJUN and CREB have been correlated with maximal steroidogenesis and activation of Nr4a1 promoter activity (Martin \& Tremblay 2009, Manna et al. 2011). As CREB and cJUN dimerize and bind to target promoters (Hai \& Curran 1991), we assessed

A

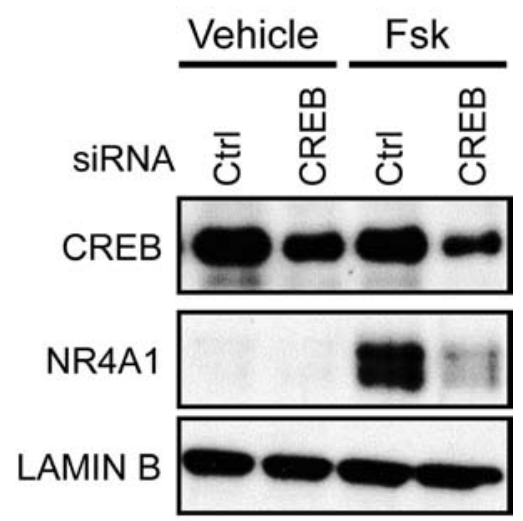

B

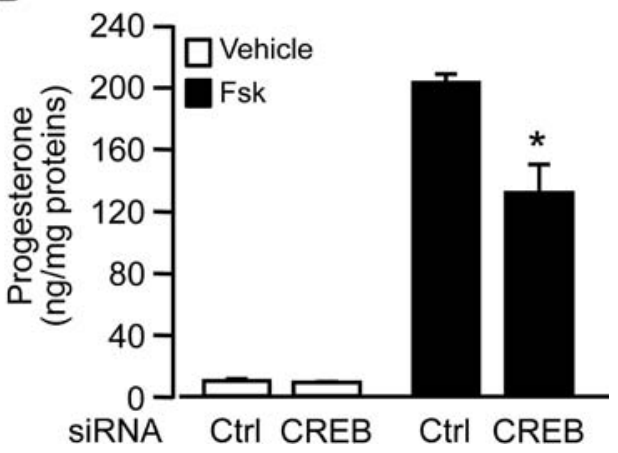

Figure 7

siRNA-mediated knockdown of CREB impairs NR4A1 expression and steroidogenesis in MA-10 Leydig cells. (A) CREB and NR4A1 protein levels were determined by western blot using nuclear extract from MA-10 Leydig cells 2 days post-transfection of either control siRNAs (Ctrl) or siRNAs against CREB, followed by a 2 h-treatment with $10 \mu \mathrm{M}$ Fsk. (B) Progesterone secreted by MA-10 Leydig cells treated for $4 \mathrm{~h}$ with either DMSO or $10 \mu \mathrm{M}$ Fsk was quantified by ELISA 2 days post-transfection of either control siRNAs (Ctrl) or siRNAs against CREB. An asterisk indicates a statistically significant difference. the impact of CREB knockdown on NR4A1 expression and steroidogenesis. As shown in Fig. 7A, siRNA-mediated knockdown of CREB was sufficient to significantly reduce the Fsk/cAMP-mediated increase in NR4A1 protein levels in MA-10 Leydig cells. Depletion of CREB also decreased Fsk-induced progesterone production (Fig. 7B). These results indicate that the pro-steroidogenic role of CREB occurs primarily in cAMP/Ca ${ }^{2+}$-stimulated cells and position CREB upstream of NR4A1 in a regulatory cascade in hormone-induced MA-10 Leydig cells.

\section{Discussion}

While studies with cells derived from rodents (Sullivan \& Cooke 1986, Kumar et al. 1994, Lee et al. 2011), bovine (Cherradi et al. 1997), and humans (Clark et al. 1995) have revealed that the $\mathrm{Ca}^{2+}$ signaling pathway is crucial to steroid hormone synthesis, health, and reproductive function, very little is known about the transcriptional cascade initiated upon increase in cytoplasmic $\mathrm{Ca}^{2+}$ levels. We and others have recently showed that the $\mathrm{Ca}^{2+}$-dependent increase in steroid synthesis requires the acute expression of STAR in Leydig cells (Manna et al. 1999, Abdou et al. 2013). This explains, at least in part, the mechanism of actions of several antihypertensive drugs targeting $\mathrm{Ca}^{2+}$ channels that are known to impair steroidogenesis and spermatogenesis in rodents (Almeida et al. 2000, Lee et al. 2011). Surprisingly, a detailed characterization of the $\mathrm{Ca}^{2+-m e d i a t e d ~ S t a r-d e p e n d e n t ~ a c u t e ~ s t e r o i d o g e n e s i s ~ i s ~}$ still lacking. Our previous study was the first to identify NR4A1, but not NR5A1, as one of the main downstream effector of $\mathrm{Ca}^{2+}$-dependent increase in Star expression and thus steroidogenesis in Leydig cells (Abdou et al. 2013). In this study, we identified key downstream effectors of the $\mathrm{Ca}^{2+}$-signaling pathway involved in the transcriptional regulation of $\mathrm{Nr4a1}$ by mapping $\mathrm{Ca}^{2+}$-responsive elements located at -319 (MEF2), -285 (MEF2), and -255 (CRE/AP1) of the rat $\mathrm{Nr} 4 a 1$ gene. Lastly, we identified p300 and pCREB as regulators targeted by the $\mathrm{Ca}^{2+}$ pathway to stimulate $\mathrm{Nr} 4 \mathrm{a} 1$ gene expression in MA-10 Leydig cells, and showed that CREB is required for NR4A1 expression and steroidogenesis.

\section{Collective contribution of MEF2, CREB, and AP1 transcription factors to the regulation of $\mathrm{Ca}^{2+-}$ dependent $\mathrm{Nr} 4 \mathrm{a} 1$ expression}

The induction kinetic of the immediate early response gene Nr4a1 is correlated with the chromatin state of its locus. For instance, in the renal medulla-derived PC12 cell line, the acetylation level of Lys14-H3 on the Nr4a1 gene was shown to be

Published by Bioscientifica Ltd 
increased $1 \mathrm{~h}$ following cAMP stimulation, while decreasing to basal levels $3 \mathrm{~h}$ later (Maruoka et al. 2010). This explains, at least in part, the peak in Nr4a1 expression levels at $2 \mathrm{~h}$ post-Fsk treatment before decreasing to basal levels at $4 \mathrm{~h}$ (Martin etal. 2008, Martin etal. 2009). Such promoter changes require an active modulation of acetylase (co-activator) and deacetylase (co-repressor) recruitment following cell stimulation, and this is ubiquitously mediated via interactions with transcription factors because acetylases and deacetylases do not directly bind to DNA. For instance, the transcriptional activity of MEF2 factors is modulated by interactions with coactivators and co-repressors depending on the cellular state in various tissues (Lu et al. 2000, McKinsey et al. 2000, Youn \& Liu 2000, Youn et al. 2000). The activation of MEF2 transactivation properties by CAMKI/II/IV occurs by a de-repression mechanism that displaces the co-repressors HDAC4/5 from their promoter targets (Lu et al. 2000, McKinsey et al. 2000, Passier et al. 2000, Linseman et al. 2003), thus allowing a permissive transcriptional state and recruitment of the p300 acetylase leading to histone acetylation.

Inhibition of PKA was found to abrogate the cAMPmediated increase in Lys14-H3 acetylation at the Nr4a1 promoter (Maruoka et al. 2010). Furthermore, it has been shown that the cAMP pathway enhances RyRdependent $\mathrm{Ca}^{2+}$ release, which occurs most likely through PKA-dependent phosphorylation of RyRs (Takasago et al. 1989, Yoshida et al. 1992, Kumar et al. 1994, Igami et al. 1999, Costa et al. 2010, Costa et al. 2011). Taking all these into consideration, it is likely that the $\mathrm{Ca}^{2+}$ pathway might also modulate the chromatin state at the Nr4a1 gene promoter in Leydig cells, in addition to the general cAMP-CREB-CBP/p300 cascade. This is supported by our current results showing that pCREB and the p300 acetylase are recruited to the Nr4a1 promoter as early as $30 \mathrm{~min}$ following Fsk stimulation, but this recruitment is prevented when the $\mathrm{Ca}^{2+}$ signaling pathway is disrupted. In addition to the ability of CREB to recruit co-activators, MEF2 along with other co-factors like NFAT can increase p300 recruitment to the Nr4a1 promoter, as shown in T cells (Youn et al. 2000).

It is likely that one of the roles of MEF2 transcription factors is to constitutively silence gene expression in the absence of external stimuli, thus only allowing a transient increase when needed, similar to the dynamic profile of Nr4a1 expression as shown in neural precursor PC12 and in MA-10 Leydig cells (Martin et al. 2008, Lam et al. 2010, Maruoka et al. 2010). This strategy not only helps the cell conserve energy but also avoids the initiation of any cellular process that might alter the cell basal physiology, like differentiation and steroidogenesis (Martin et al. 2008, Maruoka et al. 2010), or cause cell death [(Bouzas-Rodriguez et al. 2012) and reviewed in
(Deutsch et al. 2012)]. As MEF2 is associated with co-repressors such as HDACs on the Nr4a1 gene promoter in unstimulated cells, it indirectly prevents unnecessary cellular processes to take place. Thus any physiological stimulus that might alter the balance of co-repressor and co-activator recruitment to the Nr4a1 gene promoter most likely changes the interaction profile between MEF2 and its partners, including HDAC4/5 and p300. In such case, MEF2 can act as a switch allowing a transient transactivation of Nr4a1 gene expression, and thus Star expression and steroidogenesis, similar to the transient elevation of intracellular cAMP and $\mathrm{Ca}^{2+}$ levels following trophic hormone stimulation of Leydig cells.

\section{Several signaling pathways converge to modulate Nr4a1 expression}

In addition to the cAMP-PKA-CREB pathway, the protein kinase C (PKC) has also been shown to regulate Nr4a1 expression in T cells by targeting the AP1/CRE elements located at $-255 \mathrm{bp}$ (Kim et al. 2005). This occurs most likely through cJUN because PKC regulates its transactivation through ATF2 in a p300-dependent manner (Yamasaki et al. 2009). Interestingly, the cJUN N-terminal kinase (JNK) can also activate the transactivation activity of cJUN in a $\mathrm{Ca}^{2+-}$ dependent manner in immune cells (Su et al. 1994), in agreement with our results in Leydig cells. It is known that the trophic hormone stimulation of G-protein-coupled receptors increases the intracellular levels of cAMP, $\mathrm{Ca}^{2+}$, and $\mathrm{DAG} / \mathrm{IP}_{3}$ to amplify its signaling properties through PKA/CAMK/PKC. Interestingly, all of the pathways appear to converge on specific transcription factors, thus allowing proper expression/activity of the factors involved in a given cellular process, such as steroidogenesis.

In conclusion, this study suggests that, in addition to the well-known cAMP pathway, the $\mathrm{Ca}^{2+}$ signaling pathway activates Nr4a1 gene transcription partially through AP1, CREB, and MEF2 transcription factors that will ultimately recruit the ubiquitous co-activator p300 to the promoter. In addition, these results convey that the cAMP and $\mathrm{Ca}^{2+}$ pathways converge to modulate Nr4a1 expression and ultimately hormone-induced steroidogenesis in MA-10 Leydig cells.

Declaration of interest

The authors declare that there is no conflict of interest that could be perceived as prejudicing the impartiality of the research reported.

\section{Funding}

J J T holds a Chercheur-Boursier Scholarship from the Fonds de recherche du Québec - Santé. This work was funded by a grant from the Natural Sciences and Engineering Research Council of Canada (262224 to JJT).

Published by Bioscientifica Ltd. 


\section{Author contribution}

H S A and N M R performed the research. H S A, N M R, and J J T analyzed the data. H S A and J J T designed the research study and wrote the manuscript.

\section{Acknowledgments}

The authors thank Dr Mario Ascoli for generously providing the MA-10 cell line used in this study, Dr Dany Chalbos for the cJUN expression vector, Dr Marc Montminy for the CREB expression vector, and François Péloquin for generating the Nr4a1 promoter construct mutated in all three AP1/ CRE elements.

\section{References}

Abdou HS, Bergeron F \& Tremblay JJ 2014 A cell-autonomous molecular cascade initiated by AMP-activated protein kinase represses steroidogenesis. Molecular and Cellular Biology 34 4257-4271. (doi:10.1128/MCB.00734-14)

Abdou HS, Villeneuve G \& Tremblay JJ 2013 The calcium signaling pathway regulates leydig cell steroidogenesis through a transcriptional cascade involving the nuclear receptor NR4A1 and the steroidogenic acute regulatory protein. Endocrinology $\mathbf{1 5 4}$ 511-520. (doi:10.1210/en.2012-1767)

Almeida SA, Teofilo JM, Anselmo Franci JA, Brentegani LG \& Lamano-Carvalho TL 2000 Antireproductive effect of the calcium channel blocker amlodipine in male rats. Experimental and Toxicologic Pathology 52 353-356. (doi:10.1016/S0940-2993(00)80062-7)

Ascoli M 1981 Characterization of several clonal lines of cultured Leydig tumor cells: Gonadotropin receptors and steroidogenic responses. Endocrinology 108 88-95. (doi:10.1210/endo-108-1-88)

Bassett MH, Suzuki T, Sasano H, De Vries CJ, Jimenez PT, Carr BR \& Rainey WE 2004a The orphan nuclear receptor NGFIB regulates transcription of 3beta-hydroxysteroid dehydrogenase. implications for the control of adrenal functional zonation. Journal of Biological Chemistry 279 37622-37630. (doi:10.1074/jbc. M405431200)

Bouzas-Rodriguez J, Zarraga-Granados G, Sanchez-Carbente Mdel R, Rodriguez-Valentin R, Gracida X, Anell-Rendon D, Covarrubias L \& Castro-Obregon S 2012 The nuclear receptor NR4A1 induces a form of cell death dependent on autophagy in mammalian cells. PLoS One 7 e46422. (doi:10.1371/journal.pone.0046422)

Cherradi N, Rossier MF, Vallotton MB, Timberg R, Friedberg I, Orly J, Wang XJ, Stocco DM \& Capponi AM 1997 Submitochondrial distribution of three key steroidogenic proteins (steroidogenic acute regulatory protein and cytochrome p450scc and 3betahydroxysteroid dehydrogenase isomerase enzymes) upon stimulation by intracellular calcium in adrenal glomerulosa cells. Journal of Biological Chemistry 272 7899-7907. (doi:10.1074/ jbc.272.12.7899)

Clark BJ, Pezzi V, Stocco DM \& Rainey WE 1995 The steroidogenic acute regulatory protein is induced by angiotensin II and $\mathrm{K}+$ in $\mathrm{H} 295 \mathrm{R}$ adrenocortical cells. Molecular and Cellular Endocrinology 115 215-219. (doi:10.1016/0303-7207(95)03683-0)

Costa RR, Reis RI, Aguiar JF \& Varanda WA 2011 Luteinizing hormone (LH) acts through PKA and PKC to modulate T-type calcium currents and intracellular calcium transients in mice Leydig cells. Cell Calcium 49 191-199. (doi:10.1016/j.ceca.2011.02.003)

Costa RR, Varanda WA \& Franci CR 2010 A calcium-induced calcium release mechanism supports luteinizing hormone-induced testosterone secretion in mouse Leydig cells. American Journal of Physiology. Cell Physiology 299 C316-C323. (doi:10.1152/ ajpcell.00521.2009)
Daems C, Di-Luoffo M, Paradis E \& Tremblay JJ 2015 MEF2 Cooperates with Forskolin/cAMP and GATA4 to regulate star gene expression in mouse MA-10 Leydig cells. Endocrinology 156 2693-2703. (doi:10.1210/en.2014-1964)

Daems C, Martin LJ, Brousseau C \& Tremblay JJ 2014 MEF2 is restricted to the male gonad and regulates expression of the orphan nuclear receptor NR4A1. Molecular Endocrinology 28 886-898. (doi:10.1210/ me.2013-1407)

Deutsch AJ, Angerer H, Fuchs TE \& Neumeister P 2012 The nuclear orphan receptors NR4A as therapeutic target in cancer therapy. Anticancer Agents in Medicinal Chemistry 12 1001-1014. (doi:10.2174/187152012803529619)

Dufau ML, Winters CA, Hattori M, Aquilano D, Baranao JL, Nozu K, Baukal A \& Catt KJ 1984 Hormonal regulation of androgen production by the Leydig cell. Journal of Steroid Biochemistry 20 161-173. (doi:10.1016/0022-4731(84)90203-6)

Fahrner TJ, Carroll SL \& Milbrandt J 1990 The NGFI-B protein, an inducible member of the thyroid/steroid receptor family, is rapidly modified posttranslationally. Molecular and Cellular Biology 10 6454-6459. (doi:10.1128/MCB.10.12.6454)

Hai T \& Curran T 1991 Cross-family dimerization of transcription factors Fos/Jun and ATF/CREB alters DNA binding specificity. PNAS 88 3720-3724. (doi:10.1073/pnas.88.9.3720)

Hansson V, Skalhegg BS \& Tasken K 2000 Cyclic-AMP-dependent protein kinase (PKA) in testicular cells. Cell specific expression, differential regulation and targeting of subunits of PKA. Journal of Steroid Biochemistry and Molecular Biology 73 81-92. (doi:10.1016/S09600760(99)00077-1

Igami K, Yamaguchi N \& Kasai M 1999 Regulation of depolarizationinduced calcium release from skeletal muscle triads by cyclic AMPdependent protein kinase. Japanese Journal of Physiology 49 81-87. (doi:10.2170/jjphysiol.49.81)

Inaoka Y, Yazawa T, Uesaka M, Mizutani T, Yamada K \& Miyamoto K 2008 Regulation of NGFI-B/Nur77 gene expression in the rat ovary and in leydig tumor cells MA-10. Molecular Reproduction and Development 75 931-939. (doi:10.1002/mrd.20788)

Kim H, Lee JE, Kim BY, Cho EJ, Kim ST \& Youn HD 2005 Menin represses JunD transcriptional activity in protein kinase $\mathrm{C}$ thetamediated Nur77 expression. Experimental and Molecular Medicine $\mathbf{3 7}$ 466-475. (doi:10.1038/emm.2005.57)

Kumar S, Blumberg DL, Canas JA \& Maddaiah VT 1994 Human chorionic gonadotropin (hCG) increases cytosolic free calcium in adult rat Leydig cells. Cell Calcium 15 349-355. (doi:10.1016/01434160(94)90010-8)

Lam BY, Zhang W, Ng DC, Maruthappu M, Roderick HL \& Chawla S 2010 CREB-dependent Nur77 induction following depolarization in PC12 cells and neurons is modulated by MEF2 transcription factors. Journal of Neurochemistry 112 1065-1073. (doi:10.1111/ j.1471-4159.2009.06521.x)

Lee JH, Ahn HJ, Lee SJ, Gye MC \& Min CK 2011 Effects of L- and T-type $\mathrm{Ca}(2)(+)$ channel blockers on spermatogenesis and steroidogenesis in the prepubertal mouse testis. Journal of Assisted Reproduction and Genetics 28 23-30. (doi:10.1007/s10815-010-9480-x)

Li QX, Ke N, Sundaram R \& Wong-Staal F 2006 NR4A1, 2, 3 - an orphan nuclear hormone receptor family involved in cell apoptosis and carcinogenesis. Histology and Histopathology 21 533-540.

Linseman DA, Bartley CM, Le SS, Laessig TA, Bouchard RJ, Meintzer MK, Li M \& Heidenreich KA 2003 Inactivation of the myocyte enhancer factor- 2 repressor histone deacetylase- 5 by endogenous $\mathrm{Ca}(2+) /$ calmodulin-dependent kinase II promotes depolarization-mediated cerebellar granule neuron survival. Journal of Biological Chemistry 278 41472-41481. (doi:10.1074/jbc.M307245200)

Lu J, McKinsey TA, Nicol RL \& Olson EN 2000 Signal-dependent activation of the MEF2 transcription factor by dissociation from histone deacetylases. PNAS 97 4070-4075. (doi:10.1073/ pnas.080064097)

Published by Bioscientifica Ltd. 
Manna PR, Pakarinen P, El-Hefnawy T \& Huhtaniemi IT 1999 Functional assessment of the calcium messenger system in cultured mouse Leydig tumor cells: Regulation of human chorionic gonadotropininduced expression of the steroidogenic acute regulatory protein. Endocrinology 140 1739-1751. (doi:10.1210/endo.140.4.6650)

Manna PR, Soh JW \& Stocco DM 2011 The involvement of specific PKC isoenzymes in phorbol ester-mediated regulation of steroidogenic acute regulatory protein expression and steroid synthesis in mouse Leydig cells. Endocrinology 152 313-325. (doi:10.1210/en.2010-0874)

Martin LJ, Boucher N, Brousseau C \& Tremblay JJ 2008 The orphan nuclear receptor NUR77 regulates hormone-induced StAR transcription in Leydig cells through cooperation with $\mathrm{Ca}^{2+}$ calmodulin-dependent protein kinase I. Molecular Endocrinology 22 2021-2037. (doi:10.1210/me.2007-0370)

Martin LJ, Boucher N, El-Asmar B \& Tremblay JJ 2009 cAMP-induced expression of the orphan nuclear receptor Nur77 in MA-10 Leydig cells involves a CaMKI pathway. Journal of Andrology 30 134-145. (doi:10.2164/jandrol.108.006387)

Martin LJ \& Tremblay JJ 2005 The human 3beta-hydroxysteroid dehydrogenase/Delta5-Delta4 isomerase type 2 promoter is a novel target for the immediate early orphan nuclear receptor Nur77 in steroidogenic cells. Endocrinology 146 861-869. (doi:10.1210/ en.2004-0859)

Martin LJ \& Tremblay JJ 2009 The nuclear receptors NUR77 and SF1 play additive roles with c-JUN through distinct elements on the mouse Star promoter. Journal of Molecular Endocrinology 42 119-129. (doi:10.1677/JME-08-0095)

Maruoka H, Sasaya H, Shimamura Y, Nakatani Y, Shimoke K \& Ikeuchi T 2010 Dibutyryl-cAMP up-regulates nur77 expression via histone modification during neurite outgrowth in PC12 cells. Journal of Biochemistry 148 93-101. (doi:10.1093/jb/mvq036)

Mayr B \& Montminy M 2001 Transcriptional regulation by the phosphorylation-dependent factor CREB. Nature Reviews Molecular Cell Biology 2 599-609. (doi:10.1038/35085068)

McKinsey TA, Zhang CL, Lu J \& Olson EN 2000 Signal-dependent nuclear export of a histone deacetylase regulates muscle differentiation. Nature 408 106-111. (doi:10.1038/35040593)

Passier R, Zeng H, Frey N, Naya FJ, Nicol RL, McKinsey TA, Overbeek P, Richardson JA, Grant SR \& Olson EN 2000 CaM kinase signaling induces cardiac hypertrophy and activates the MEF2 transcription factor in vivo. Journal of Clinical Investigation 105 1395-1406. (doi:10.1172/JCI8551)

Philips A, Lesage S, Gingras R, Maira MH, Gauthier Y, Hugo P \& Drouin J 1997 Novel dimeric Nur77 signaling mechanism in endocrine and lymphoid cells. Molecular and Cellular Biology 17 5946-5951. (doi:10.1128/MCB.17.10.5946)

Qamar I, Gong EY, Kim Y, Song CH, Lee HJ, Chun SY \& Lee K 2010 Anti-steroidogenic factor ARR19 inhibits testicular steroidogenesis through the suppression of Nur77 transactivation. Journal of Biological Chemistry 285 22360-22369. (doi:10.1074/jbc. M109.059949)

Sheng M, McFadden G \& Greenberg ME 1990 Membrane depolarization and calcium induce c-fos transcription via phosphorylation of transcription factor CREB. Neuron 4 571-582. (doi:10.1016/08966273(90)90115-V)

Sheng M, Thompson MA \& Greenberg ME 1991 CREB: A Ca(2+)-regulated transcription factor phosphorylated by calmodulin-dependent kinases. Science 252 1427-1430. (doi:10.1126/science.1646483)

Song KH, Park JI, Lee MO, Soh J, Lee K \& Choi HS 2001 LH induces orphan nuclear receptor Nur77 gene expression in testicular
Leydig cells. Endocrinology 142 5116-5123. (doi:10.1210/ endo.142.12.8525)

Stocco CO, Lau LF \& Gibori G 2002 A calcium/calmodulin-dependent activation of ERK1/2 mediates JunD phosphorylation and induction of nur77 and 20alpha-hsd genes by prostaglandin F2alpha in ovarian cells. Journal of Biological Chemistry 277 3293-3302. (doi:10.1074/jbc. M110936200)

Su B, Jacinto E, Hibi M, Kallunki T, Karin M \& Ben-Neriah Y 1994 JNK is involved in signal integration during costimulation of $\mathrm{T}$ lymphocytes. Cell 77 727-736. (doi:10.1016/0092-8674(94)90056-6)

Sullivan MH \& Cooke BA 1986 The role of $\mathrm{Ca}^{2+}$ in steroidogenesis in Leydig cells. Stimulation of intracellular free $\mathrm{Ca}^{2+}$ by lutropin (LH), luliberin (LHRH) agonist and cyclic AMP. Biochemical Journal 236 45-51. (doi:10.1042/bj2360045)

Takasago T, Imagawa T \& Shigekawa M 1989 Phosphorylation of the cardiac ryanodine receptor by cAMP-dependent protein kinase. Journal of Biochemistry 106 872-877.

Teyssier C, Belguise K, Galtier F \& Chalbos D 2001 Characterization of the physical interaction between estrogen receptor alpha and JUN proteins. Journal of Biological Chemistry 276 36361-36369. (doi:10.1074/jbc.M101806200)

Tsuda T, Hamamori Y, Yamashita T, Fukumoto Y \& Takai Y 1986 Involvement of three intracellular messenger systems, protein kinase $\mathrm{C}$, calcium ion and cyclic AMP, in the regulation of c-fos gene expression in Swiss 3T3 cells. FEBS Letters 208 39-42. (doi:10.1016/0014-5793(86)81527-7)

Vo N \& Goodman RH 2001 CREB-binding protein and p300 in transcriptional regulation. Journal of Biological Chemistry 276 13505-13508. (doi:10.1074/jbc.R000025200)

Wilson TE, Fahrner TJ \& Milbrandt J 1993 The orphan receptors NGFI-B and steroidogenic factor 1 establish monomer binding as a third paradigm of nuclear receptor-DNA interaction. Molecular and Cellular Biology 13 5794-5804. (doi:10.1128/ MCB.13.9.5794)

Woronicz JD, Lina A, Calnan BJ, Szychowski S, Cheng L \& Winoto A 1995 Regulation of the Nur77 orphan steroid receptor in activationinduced apoptosis. Molecular and Cellular Biology 15 6364-6376. (doi:10.1128/MCB.15.11.6364)

Yamasaki T, Takahashi A, Pan J, Yamaguchi N \& Yokoyama KK 2009 Phosphorylation of activation transcription factor- 2 at serine 121 by protein kinase $\mathrm{C}$ controls c-Jun-mediated activation of transcription. Journal of Biological Chemistry 284 8567-8581. (doi:10.1074/jbc. M808719200)

Yoshida A, Takahashi M, Imagawa T, Shigekawa M, Takisawa H \& Nakamura T 1992 Phosphorylation of ryanodine receptors in rat myocytes during beta-adrenergic stimulation. Journal of Biochemistry 111 186-190.

Youn HD, Chatila TA \& Liu JO 2000 Integration of calcineurin and MEF2 signals by the coactivator p300 during T-cell apoptosis. EMBO Journal 19 4323-4331. (doi:10.1093/emboj/19.16.4323)

Youn HD \& Liu JO 2000 Cabin1 represses MEF2-dependent Nur77 expression and $\mathrm{T}$ cell apoptosis by controlling association of histone deacetylases and acetylases with MEF2. Immunity 13 85-94. (doi:10.1016/S1074-7613(00)00010-8)

Youn HD, Sun L, Prywes R \& Liu JO 1999 Apoptosis of T cells mediated by $\mathrm{Ca}^{2+}$-induced release of the transcription factor MEF2. Science $\mathbf{2 8 6}$ 790-793. (doi:10.1126/science.286.5440.790)

Zhang P \& Mellon SH 1997 Multiple orphan nuclear receptors converge to regulate rat P450c17 gene transcription: Novel mechanisms for orphan nuclear receptor action. Molecular Endocrinology 11 891-904. (doi:10.1210/mend.11.7.9940)

Received in final form 25 November 2015

Accepted 8 December 2015

Accepted Preprint published online 8 December 2015 http://jme.endocrinology-journals.org

DOI: 10.1530/JME-15-0202
(C) 2016 Society for Endocrinology Printed in Great Britain
Published by Bioscientifica Ltd 